\title{
EDUCAÇÃO PROFISSIONAL E CAPITALISMO DEPENDENTE: O ENIGMA DA FALTA E SOBRA DE PROFISSIONAIS QUALIFICADOS
}

\author{
PROFESSIONAL EDUCATION AND DEPENDENT CAPITALISM:THE ENIGMA OF THE LACK AND \\ EXCESS OF QUALIFIED PROFESSIONALS
}

\author{
Gaudêncio Frigotto ${ }^{1}$
}

Resumo O objetivo deste texto é debater a reforma da educação profissional e seu ajuste às relações sociais de produção capitalista. O texto enfatiza, inicialmente, como os espaços da produção teórica e da ação política se relacionam e se diferenciam e, a seguir, como, na impossibilidade de resolver o conflito indivíduo e sociedade mercantil, o pensamento liberal efetiva um deslocamento da teoria econômica liberal para a doutrina neoliberal. É neste contexto que ganham compressão a reforma da educação profissional na década de 1990 e o deslocamento dos conceitos de qualificação e emprego para as noções de competência e empregabilidade. Por fim, o texto busca analisar a especificidade da reforma da educação profissional em países como o Brasil, de capitalismo dependente e desenvolvimento desigual e combinado. Especificidade esta que impede ao pensamento liberal e neoliberal superar a visão dualista e fixar-se em chavões como o que está atualmente corrente - o do 'apagão' de profissionais qualificados para dar conta às demandas do mercado de trabalho. Ao contrário, o texto busca analisar a aparente contradição entre a real falta de mão-de-obra qualificada e, ao mesmo tempo, a sobra com o êxodo para o mercado internacional dos jovens melhor qualificados.

Palavras-chave educação profissional; competência; empregabilidade; capitalismo dependente; contradições.
Abstract The purpose of this article is to debate professional education reforms and its adjustment to the social relations developed in capitalistic production. Initially, the text highlights how the theoretical production and political action spheres interrelate and differ from each other and, then, how, when it is impossible to solve the conflict between the individual and the consumer society, the liberal mindset transports the liberal economic theory to the neoliberal doctrine. It is in this context that not only the professional education reform undertaken in the 1990's, but the qualification and job concept movement to the competency and employability spheres become more compact. Finally, the text seeks to analyze professional education reform specificities in countries such as Brazil, where capitalism is dependent and development unequal and concerted. Such specificity keeps liberal and neoliberal thought from overcoming the dualistic view and leads to the establishment of clichés such as the current lack of qualified professionals to deal appropriately with the market demands. On the contrary, the text seeks to analyze the apparent contradiction between the lack of qualified labor and, meanwhile, the excess that causes the exodus of better-qualified young people to the international market.

Keywords professional education; competency; employability; dependent capitalism; contradictions. 


\section{Educação profissional e capitalismo dependente: o enigma da falta e sobra de profissionais qualificados}

O texto apresentado por Acacia Kuenzer, como ela mesma sinaliza, é resultado dos estudos que tem realizado, "na última década, sobre políticas e programas de educação profissional". Se o que aqui apresenta é síntese de resultados de pesquisa de um recorte da última década, o eixo teórico e a relação deste com a pesquisa empírica e os embates no plano político da práxis, em diferentes espaços, ocupam a autora nas três últimas décadas.

Com efeito, como poucos intelectuais da área da educação, Kuenzer reúne o permanente exercício da produção teórica, do debate metodológico no campo do materialismo histórico, acentuados na pesquisa empírica e no diálogo crítico e interfaces com seu grupo de pesquisa e com vários outros grupos nacionais e internacionais que analisam a relação trabalho, conhecimento e educação.

Do mesmo modo, também, experimentou, em diferentes âmbitos (próreitoria, diretoria de faculdade, diretoria de área no Conselho Nacional de Desenvolvimento Científico e Tecnológico (CNPq) e Instituto Nacional de Estudos e Pesquisas Educacionais Anísio Teixeira - Inep), a atividade política de direção e gestão. Isso lhe permite perceber com acuidade que o campo da produção teórica e da ação política se relacionam ou deveriam se relacionar permanentemente, mas que se efetivam de modo diverso e com graus de autonomia relativa também diversos.

Na produção teórica, a exigência básica da atividade intelectual é ser 'radical' (que vai à raiz), já que o que se disputam é o sentido e significado da historicidade do real. Não há como somar ou, pior ainda, negociar sentidos e significados da realidade histórica numa sociedade de classes. O antagonismo e o conflito são inerentes à sua estrutura orgânica. A teoria social crítica é fundamental para evidenciar o conflito e antagonismo de classe e, se efetivamente crítica, vale dizer que historiciza o real, torna-se uma força material política, como assinala Marx, na luta de classes. A ação política nas condições objetivas de uma sociedade de classes depende da relação de forças. Mesmo para aqueles que lutamos e nos situamos no âmbito do 'partido revolucionário', no sentido dado por Antonio Gramsci - partido que tem como projeto ideológico e teórico-prático a superação do capitalismo - implicam lutas e vitórias parciais, alianças estratégicas e táticas, cujo resultado nem sempre é o que esperamos e no qual apostamos. Entretanto isso não implica declinar e transigir no plano ideológico e ético-político. A atividade teórica e de parlamentar de Gramsci elucidam bem o que queremos assinalar. Não se trata de dois Gramscis, mas de um mesmo que se movimenta em esferas de ação diversas.

O texto síntese de Kuenzer expressa este duplo movimento ao trabalhar, no primeiro ponto, a adaptação da educação profissional à produção e acumu- 
lação flexíveis, não sem contradições e embates e, no segundo, as políticas da última década que concorrem para isso e, por último, o horizonte de luta no plano teórico e da práxis para aqueles que estão empenhados na superação das relações sociais capitalistas.

Posto este comentário mais geral, atenho-me a alguns aspectos específicos do texto realçando algumas questões com o intuito de estimular a pesquisa e o debate.

\section{Educação básica e profissionais na lógica unidimensional mercantil e a conformação psicofísica do cidadão produtivo flexível}

A análise de Kuenzer explicita, de forma muito consistente, a tendência da formação do trabalhador no processo de produção e acumulação flexível. A década analisada pela autora nos sinaliza uma derrota, ainda que não o fracasso, das lutas da década de 1980 centradas na concepção de educação básica omnilateral e politécnica, ou tecnológica, condições para o desenvolvimento de sujeitos emancipados. Há uma regressão teórica e política, sob a ideologia neoliberal, focando os processos formativos dentro do ideário do 'cidadão produtivo' subordinado à lógica mercantil (Frigotto e Ciavatta, 2006). Trata-se, como lembra Carlos Paris (2002), de formar um indivíduo que faça bem feito o que se lhe pedem e que acredite que não lhe compete meter-se nas questões políticas, já que estas são prerrogativas de especialistas.

A produção do trabalhador flexível tem como pressuposto que o que comanda e subordina a sua formação é o fetiche e determinismo tecnológicos ${ }^{2}$. Ou seja, a hipertrofia do capital morto, expresso na 'nova' base tecnológica de natureza digital-molecular nos processos de produção e de organização e gestão da mesma, é concebida como natural e despida de relações de poder, relações de classe. Por isso, a educação que se demanda não é qualquer educação. Trata-se de uma educação de 'qualidade total'. Vale dizer, aquela que possui as 'competências' que se enquadram na lógica do 'cidadão produtivo' prontamente adaptável e que produz em tempo mínimo, qualidade máxima e cuja mercadoria ou serviço se realizem no mercado imediatamente.

Uma flexibilidade, também, que entenda que a instabilidade ou a simples dispensa de seu trabalho faz parte desta nova (des)ordem das relações sociais de produção. Trata-se de uma educação geral, básica - se possível na dose certa - de caráter mais universal mas, ao mesmo tempo, também restrita e diferenciada. Essa é uma contradição insanável no plano teórico e ético-político do pensamento e moral capitalistas. No plano teórico, fixa-se na particularidade dos interesses de produtividade e do lucro máximo e, no plano ético, fixa-se na moral e no direito privado, jamais na universalidade de condições de igualdade efetiva nas condições da produção social da existência humana. 
A formação do trabalhador adequada à flexibilidade do processo produtivo e da acumulação é incompatível com a educação omnilateral e politécnica e de escola unitária e centra-se na concepção de formação polivalente. A escola dual recebe, neste contexto, novas determinações. A escolaridade e o tipo de qualidade de educação para classe trabalhadora podem e devem ser diferenciados no conteúdo e no método, com menos tempo, conteúdo aligeirado mais restrito (tecnicista) e mais barato. O decreto $\mathrm{n}^{\circ}$ 2.208/97, síntese das demandas do capital no Brasil desde o processo constituinte, explicita de forma inequívoca a base conceptual e legal dos processos de formação que lhes interessa. Como veremos no próximo item, isto decorre de determinações específicas da sociedade brasileira, cuja burguesia tem optado por um capitalismo dependente forjado na lógica do mimetismo, do endividamento externo e na subordinação consentida.

Dois aspectos, de âmbito mais superestrutural ligados à teoria ou ideologia econômica e educacional, nos parecem importantes e, por isso, devem ser incorporados de forma mais explícita na análise de Kuenzer para qualificar, por um lado, o que 'denomina de arranjos flexíveis de competências diferenciadas e a relativização da qualificação com foco na ocupação', já que esta é também flexível; por outro, a privatização das políticas e do pensamento educacional e a base jurídica que lhe dá sustentação.

O primeiro aspecto opera-se no âmbito da teoria econômica. Como mostra Paulani (2005), é importante destacar que a impossibilidade de solucionar o conflito indivíduo e sociedade nas relações sociais capitalistas conduziram, após quarenta anos de embate dentro dos cânones da teoria clássica e neoclássica, Hayek $(1980 ; 1987)$ a produzir uma doutrina - o neoliberalismo. Ressuscita-se, com novas roupagens e determinações, o velho liberalismo conservador baseado no credo psicológico de uma natureza humana sem história, de caráter egoísta e individualista e no credo do livre mercado e do Estado como entidade neutra e acima dos interesses de classe - hoje um Estado social mínimo e um Estado maximizado como garantia do capital. A imposição de um superávit primário, de aproximadamente $5 \%$ do Produto Interno Bruto (PIB) é uma medida da exigência absurda destas garantias.

A Dama de Ferro, como ficou conhecida Margaret Thatcher por suas políticas de caráter conservador contra a classe trabalhadora, proclamou que não via a sociedade, mas somente os indivíduos. Na verdade, Thatcher estava ancorada numa ampla literatura neoconservadora, baseada no fetichismo e determinismo tecnológicos, que difunde as noções de sociedade pós-industrial, sociedade do conhecimento, sociedade pós-classista. Entre os principais propagadores dessa literatura, destacam-se: Peter Drucker (1993), Alvin Toffler (1985), Manuel Castells (1999), Milton Friedman (1985) e Daniel Bell (1973). Por outra via, que não nos ocuparemos neste texto, surgem as teses do 
pós-modernsimo, cuja base material, como demonstra Jameson (1996), é a fragmentação do capitalismo tardio e a perspectiva da morte do sujeito.

O segundo aspecto decorre desta operação discursiva mais geral (neoliberal e pós-moderna), marcadamente ideológica, e se desdobra nas concepções de educação e formação profissional ultrafragmentárias e individualistas centradas na pedagogia ou ideologia das competências. No texto em discussão, para o que está preocupada em demonstrar, a autora utiliza o termo competência na sua significação técnica dicionarizada ${ }^{3}$. Mesmo que o seu sentido ideológico seja analisado em outros textos pela autora, parece-me importante enfatizá-lo aqui, pois é justamente a noção de competências que constitui o arcabouço pedagógico e metodológico dos processos formativos do 'cidadão produtivo' adaptado à produção e acumulação flexíveis ${ }^{4}$. Trata-se de trabalhadores que têm que se adaptar, física, psíquica e afetivamente, à lógica da produção, como assinala a autora,

"com diferentes qualificações, de modo a constituir corpos coletivos de trabalho dinâmicos, por meio de uma rede que integra deferentes formas de subcontratação e trabalho temporário e que, ao combinar diferentes estratégias de extração de mais-valia, assegura a realização da lógica mercantil".

A pedagogia das competências nos marcos da formação polivalente são adequadas, no plano das relações de trabalho, segundo Kuenzer, ao mostrar os processos de inclusão, exclusão, subcontratatação e precarização do trabalho na lógica da acumulação flexível. Nas políticas de inserção dos trabalhadores, apaga-se a perspectiva do coletivo e realça-se a competição individual. Assim é que a perspectiva do direito ao emprego, regulado por um contrato social e tendo como base a organização coletiva dos trabalhadores, dilui-se na noção de empregabilidade, cujo escopo é que cada indivíduo responde por si próprio por seu sucesso ou insucesso.

A mensagem clara é que não há mais lugar para todos, mas apenas para aqueles que se adequarem ao conjunto de competências técnicas, científicas, culturais e afetivas que o mercado reconhece como desejáveis do 'novo' cidadão produtivo. Somente este tem escrito no rosto a condição de empregável. Condição esta, de acordo com a ideologia da empregabilidade, não mais estabelecida no horizonte de longo prazo, mas somente até que as partes assim o desejarem 5 .

Por caminhos opostos, paradoxalmente, o ideário do fim das classes sociais e do conflito que as estrutura une o pensamento ou doutrina neoliberal e pós-modernismo na compreensão fragmentária da realidade. Na doutrina neoliberal, o fetiche e determinismo tecnológico eliminam o conflito de classe e a necessidade de organização coletiva, sem que se elimine o sistema capital e, portanto, suas leis básicas - a propriedade privada e a extração da mais- 
valia. Na tese pós-moderna, já estaríamos num novo paradigma, centrado nas diferenças e alteridade, depurado de qualquer estrutura, centro de poder ou dimensão de universalidade e totalidade histórica ${ }^{6}$. Por essa via, também elidem a estrutura de classe e a organização de classe, sem que o sistema capitalista tenha sido superado. O raciocínio lógico destas posturas, com argumentos diferentes, é que as análises fundadas no materialismo histórico estão superadas e viveríamos uma nova realidade histórica e, por conseqüência, um novo paradigma epistemológico, político, no mundo do trabalho e, mais amplamente, social. Uma sociedade do conhecimento e da informação, não mais uma sociedade de classes, de conflitos e antagonismos.

Diante das mudanças geradas pelo metabolismo do sistema capital impõese não confundir a aparência da mudança de modo de produção capitalista - e das categorias que nos permitem sua compreensão - com as novas formas que o mesmo assume - mais violentas e destrutivas. Daí a pertinência e a densidade da abordagem de Kuenzer, assentada no materialismo histórico, ao expor o sentido das reformas da educação profissional, na década de 1990, no ajuste ao regime de acumulação flexível na realidade brasileira.

\section{Capitalismo dependente desigual e combinado e a contradição da falta e da sobra de trabalhadores qualificados}

Se, na primeira parte do texto, Kuenzer se preocupa em nos mostrar a perspectiva da conformação mais geral dos processos formativos ao processo metabólico do sistema capital em sua forma de produção e acumulação flexível, na segunda, busca mostrar-nos como as políticas de educação profissional, especialmente a partir do segundo mandato de Fernando Henrique e ao longo do governo Lula, se filiam no fundamental a este processo adaptativo.

Com efeito, como não houve alterações efetivas no plano estrutural das relações sociais e nas políticas do denominado ajuste das economias do capitalismo dependente à nova (des)ordem da mundialização do capital, as diferenças mais significativas entre os governos de Cardoso e Lula, em termos de políticas de educação e de formação profissional, são a maior universalização das políticas focais de inclusão precária e a articulação de alguns programas antes isolados. Em função da falta de um projeto de desenvolvimento alternativo, que inclua reformas estruturais, da tradição de não construir políticas de Estado, mas de governo, da política de alianças cada vez mais conservadora e, por outra parte, do esfacelamento dos movimentos e forças da esquerda, a correlação de força, dentro do aparelho do Estado e na sociedade civil, pende cada vez mais para os processos de privatização mascarados por parcerias e pelas nomenclaturas que dissimulam este processo - organizações sociais públicas de direito privado. 
Os embates no processo de revogação do decreto 2.208/97 e na publicação do decreto $\mathrm{n}^{\circ} 5.154 / 04$, assim como o desfecho de regulamentação deste último decreto evidenciam, de forma emblemática, o que sinalizamos antes e que é evidenciado na análise de Kuenzer de forma incisiva. Neste particular, o fato do governo Lula não ter uma definição de projeto alternativo de desenvolvimento e políticas públicas a ele relacionado, no âmbito da educação em geral e formação profissional, permitiu que a regulamentação legal, no Conselho Federal de Educação, fosse definida pelas mesmas forças que legislaram sobre o decreto $\mathrm{n}^{\circ} 2.208 / 97$. Isto anulou os esforços daqueles que, de dentro do governo (poucos é verdade) e daqueles que em diferentes espaços da sociedade, estavam e estão empenhados em resgatar as lutas pela educação pública, básica ou profissional, no horizonte dos interesses da classe trabalhadora7. É por isso que a conclusão a que chega Kuenzer sobre o decreto $n^{0}$ 5.154/04 expressa a justeza do que ocorreu e uma questão para o campo da esquerda. "Assim, o decreto $\mathrm{n}^{\circ}$ 5.154/04 ampliou o leque de alternativas com o médio integrado sem que nenhuma das possibilidades anteriores, que favorecem ações privadas de formação precarizada com recursos públicos, fosse revogada".

A questão acima nos remete à necessidade de tentar entender porque, até mesmo na batalha das idéias no plano teórico, o debate sobre educação básica desinteressada e na perspectiva da politécnica e escola unitária e da articulação necessária entre educação básica desinteressada e formação profissional saíram da agenda e nos ocupamos da reestruturação produtiva e das demandas da nova subjetividade do trabalhador. No âmbito da luta política cabe perguntar por que o campo sindical e dos movimentos sociais, e até mesmo dos partidos de esquerda, se esfacelou tanto. Quem, além do Movimento dos Sem Terra (MST), apresenta hoje, no campo de esquerda, uma agenda que possa ir além do diagnóstico e da crítica?

A articulação do item um e dois da análise de Keunzer nos remete à necessidade de nos perguntarmos por que o capitalismo construído pela classe burguesa brasileira configura uma realidade aparentemente contraditória, em que os empresários e os intelectuais a seu serviço, as grandes redes de comunicação e amplos setores do campo político engrossam a surrada tese de que o que trava um maior desenvolvimento é a falta de trabalhadores qualificados, mas, ao mesmo tempo, não se dá nenhum passo substantivo para a universalização do ensino básico de nível médio, com bases materiais que permitam uma qualidade ao menos nos padrões do que ofereciam as escolas técnicas federais, hoje Cefets. Mais intrigante ainda o fato de que pesquisas evidenciam, como assinalaremos a seguir, que milhares de jovens, exatamente os mais qualificados, saem do Brasil anualmente em busca de melhor remuneração ganhando lá fora mais, fazendo o trabalho simples, do que aqui se oferece ao trabalho complexo.

A contradição é apenas aparente, pois o sistema capital domina todas as partes do mundo, mas não da mesma forma. Ele apresenta, em distintas so- 
ciedades, processos históricos específicos que engendram particularidades 8 tanto na estrutura de classes e relações de classe, quanto nos efeitos à exploração da classe trabalhadora.

"Ainda que desenvolvendo-se de maneira desigual, combinada e contraditória, o capitalismo expande-se pelas mais diferentes nações e nacionalidades, bem como culturas e civilizações, dinamizado pelos processos de concentração e centralização, concretizando a sua globalização" (Ianni, 2001, p. 78).

As análises, sobretudo de Florestan Fernandes e de Francisco de Oliveira, são fundamentais para compreender a especificidade que assume a sociedade brasileira como herdeira emblemática e reiterada de capitalismo dependente e de desenvolvimento desigual e combinado 9 .

As categorias de capitalismo dependente e desenvolvimento desigual e combinado têm íntima relação e se fundamentam nas abordagens de Marx e Engels, Lenin, Trotsky e Mandel sobre imperialismo10. Estas categorias são centrais para entender a especificidade e particularidade de como se construiu o capitalismo no Brasil, a natureza da estrutura e relações de classe e as alianças da burguesia brasileira com as burguesias do capitalismo hegemônico. Como mostra Löwy (1981; 1995), as análises do desenvolvimento desigual e combinado introduzem uma diferença crucial em relação às dos teóricos da dependência, pois, diferente destes últimos, afirmam “o caráter exclusivamente capitalista das economias latino-americanas, desde a época da colonização - na medida em que (...) trata-se mais de um amálgama entre relações de produção desiguais sob a dominação do capital" (Löwy, 1995, p. 8).

Na Crítica à razão dualista e sua atualização com o texto O ornitorrinco, Oliveira (2003) metaforicamente compara o processo de desenvolvimento construído pela burguesia brasileira a esse monstrengo, uma vez que o analfabetismo, a precária educação básica, o trabalho informal e as mais radicais formas de precarização e flexibilização do trabalho não são, ao longo de nossa história, como o pensamento dominante insiste, o entrave para o desenvolvimento, mas a forma específica de sociedade que se forjou - uma sociedade que produz a desigualdade e se alimenta dela.

Oliveira mostra-nos que, dentro desta forma societária específica, a vigência do modo de regulação fordista, tanto no plano tecnológico quanto no plano social, foi parcial e precária e, do mesmo modo, nos situamos de forma ainda mais parcial e precária na mudança técnicocientífica de natureza digital-molecular. Como assinala este autor, se a cópia já era problemática na base técnica fordista, cuja duração de utilidade era maior, agora a cópia multiplica seus custos sociais, já que a velocidade das mudanças é muitíssimo maior. Não é contraditório, pois, 
que os nexos entre ciência, produção, trabalho e vida e as demandas de educação e de formação técnico-profissional tendam a ser, também, parciais e precários.

Isto nos permite depreender e sustentar que a classe burguesa brasileira, de cultura e mentalidade escravocrata e colonizadora e historicamente associada e subordinada à classe burguesa dos centros hegemônicos do capitalismo, impediu, por diferentes mecanismos, a universalização da educação escolar básica (fundamental e média), pública e laica, mesmo nos limites dos interesses de um capitalismo avançado. Ou seja, a burguesia brasileira nunca se colocou de fato o projeto de uma escolaridade e formação técnicoprofissional para a maioria dos trabalhadores para prepará-los para o trabalho complexo que a tornasse, enquanto classe detentora do capital, em condições de concorrer com o capitalismo central.

Florestan Fernandes capta esta postura ao avaliar o debate sobre educação na Constituição de 1988: “A educação nunca foi algo de fundamental no Brasil, e muitos esperavam que isso mudasse com a convocação da Assembléia Nacional Constituinte. Mas a Constituição promulgada em 1988, confirmando que a educação é tida como assunto menor, não alterou a situação" (Fernandes, 1991).

O Brasil é o país econômica e politicamente mais importante da América Latina e o único em que o ensino médio não é obrigatório. Ele se constitui numa ausência socialmente construída, na sua quantidade e qualidade, e o indicador mais claro da opção da formação para o trabalho simples e da não preocupação com as bases da ampliação da produção científica, técnica e tecnológica. Aproximadamente $46 \%$ dos jovens têm acesso ao ensino médio, sendo que aproximadamente $60 \%$ destes o fazem no turno noturno e, grande parte, na modalidade de supletivo. No campo, apenas $12 \%$ freqüentam o ensino médio na idade e série correspondente.

Os indicadores do campo educacional são sintomas e sinais da degradação resultante de um longo processo cujo desenlace tem sido a opção da classe dominante brasileira pela inserção consentida e subordinada ao grande capital, aceitação de nosso papel subalterno na divisão internacional do trabalho, com a hipertrofia da formação para o trabalho simples. Opção esta que se afirmou mais claramente na década de 1990 com o desmonte do Estado, as privatizações e a adesão explícita ao Consenso de Washington, definindo um campo de lutas que perdurou durante todo o século XX, como mostra Fiori (2002).

Como aponta Neves, a natureza das políticas educacionais em jogo na década de 1990 dependia:

“a) das repercussões econômica e político-sociais do desenvolvimento do novo paradigma produtivo no espaço nacional; b) dos requisitos técnicos e éticopolíticos do novo conteúdo do trabalho industrial e, c) dos desdobramentos da 
luta entre a consolidação da hegemonia neoliberal e a construção de uma contrahegemonia democrática de massa" (Neves, 2000, p.180-181).

O pêndulo não se movimentou na direção das forças que lutavam por um projeto nacional popular e democrático de massa e as conseqüentes reformas estruturais, o que implicaria um projeto de educação escolar e de formação técnico-profissional dos trabalhadores para o trabalho complexo, condição para uma inserção ampla na forma que assume o processo de produção industrialmoderno com base científica digital-molecular.

Assim chegamos ao Brasil dos anos 2000, reproduzindo, de forma ampliada, o monstrengo social configurado pela metáfora do ornitorrinco e traduzido por uma pirâmide social em que, como mostram os estudos de Pochmann (2000a; 2000b; 2004), se configura um empobrecimento e esvaziamento da classe média, a polarização de lados opostos da pirâmide social com a elevação da concentração de renda e de capital e a ampliação dos 'inseridos' precariamente na base da pirâmide. Como mostra Paulani (2006), na mesma direção, o resultado de uma economia financista e rentista redunda em empregos pobres de baixo valor agregado.

Com base numa pesquisa que estamos concluindo sobre a relação entre quantidade e qualidade do ensino médio (Frigotto, 2007), constatamos que, para o tipo de opção econômica e natureza de empregos que a economia brasileira oferece, é falso o discurso corrente de empresários e seus intelectuais, assim como das redes de comunicação da falta de trabalhadores qualificados e, portanto, da necessidade do ponto de vista econômico da universalização da escola básica, especialmente média, de qualidade técnico-científica.

O primeiro aspecto da não real necessidade de uma escola básica universalizada e de qualidade é o baixo investimento em educação de nossa sociedade, em comparação com os países do capitalismo central. Isso se reflete no caráter precário das condições objetivas da oferta de um ensino médio de qualidade para todos os jovens brasileiros. $\mathrm{O}$ custo aluno-ano elevado demais no ensino médio, das antigas escolas técnicas federais, uma das justificativas para impor o decreto $\mathrm{n}^{\circ} 2.208 / 97$, não atingia os patamares médios de U\$ 4.000,00. Esta é a média do custo da educação básica em países do capitalismo central. Está é, também, a média do custo aluno em escolas privadas das capitais brasileiras freqüentadas pelos filhos da classe média.

Mas, mesmo dentro deste quadro, ao contrário do discurso corrente de falta de pessoas qualificadas, dados recentes de pesquisa sobre juventude brasileira e emprego de Márcio Pochmann, do Centro de Estudos Sindicais e de Economia do Trabalho (Cesit) da Unicamp, mostram que no Brasil “há uma crise crônica na transição do sistema educacional para o universo do emprego" (Pochmann, apud Manir, 2007, p. 1). Esta dificuldade, motivada pela opção econômica que, de acordo com este autor, perfila um pífio crescimento 
econômico há duas décadas e meia, traduz o paradoxo de que "nosso país está se transformando em grande exportador de mão-de-obra juvenil qualificada" (Pochmann, apud Manir, 2007, p. 2). A cifra alarmante apresentada é de que "perdemos, por ano, 160 mil jovens para o olho gordo do mundo. É biscoito fino, mão-de-obra qualificada que busca futuro fora do país" (Manir, 2007, p. 1).

Assim as conclusões de Kuenzer nos permitem entender que o mostrengo social construído pela burguesia brasileira tem como conseqüência correlata um sistema educacional dual, e "a continuidade de propostas precárias de educação profissional para legitimar a inclusão em trabalhos precarizados, de modo a alimentar o consumo predatório da força de trabalho".

O fato de a burguesia brasileira ou a 'elite' não entender que não há contradição no fato de haver falta e sobra, ao mesmo tempo, de gente qualificada, talvez se deva que errados mesmos são os trabalhadores, o povo, como assinala a crônica de Luis Fernando Verissimo.

\footnotetext{
“Pesquisa recente concluiu que a elite brasileira é mais moderna, ética, tolerante e inteligente do que o resto da população. Nossa elite, tão atacada através dos tempos, pode se sentir desagravada com o resultado do estudo, embora esse tenha sido até modesto nas suas conclusões. Faltou dizer que, além das suas outras virtudes, a elite brasileira é mais bem vestida do que as classes inferiores, tem melhor gosto e melhor educação, é melhor companhia em acontecimentos sociais e é incomparavelmente mais saudável. E que dentes!

A pesquisa reforça uma tese que tenho há anos segundo a qual o Brasil, para dar certo, precisa trocar de povo. Esse que está aí é de péssima qualidade. Não sei qual seria a solução. Talvez alguma forma de terceirização, substituindo-se o que existe por algo mais escandinavo" (Verissimo, 2007).

O sarcasmo do texto de Luis Fernando Verissimo nos aponta, nos leva a perceber que a tarefa da classe trabalhadora é a de lutar para ocupar o lugar da classe burguesa brasileira?
}

\section{Considerações finais}

Kuenzer, não só neste texto, mas no conjunto de sua obra, e os autores que analisam nossa formação social capitalista, anteriormente mencionados, não nos deixam dúvida de que o grande desafio é substituir, por um projeto nacional popular de caráter socialista, o projeto da burguesia brasileira. A autora conclui o seu texto apontando nesta direção: “O desafio que se coloca é o rompimento desde círculo, o que demanda novas leituras e propostas a partir de práticas que apontem para novas formas de organização social, 
que interfiram positivamente no atendimento às necessidades que vivem do trabalho."

Para que possa ocorrer o que a autora nos propõe talvez tenhamos que aprender com aqueles que, como Eric Hobsbawm, nos convidam a 'renascer das cinzas', com a convicção de que derrotas não são sinônimo de fracasso. Este autor nos ensina que os seres humanos não são feitos para as relações sociais capitalistas e que este modo de produção não é eterno, é apenas um período da história da humanidade. Aqui a radicalidade da teoria social tem de nos dar os elementos históricos para esta convicção, e que a mesma nos ajude a transformar em consciência de classe a experiência de classe (vida precária, sofrimento, privações, insegurança etc.) da grande massa de trabalhadores. Neste particular, como assinala Gramsci, a educação escolar unitária tem um papel de mediação crucial na elevação cultural para que cada trabalhador possa ler criticamente o mundo. É por isso que a luta pela escola pública, laica, universal, gratuita e unitária é pauta permanente.

No que nos concerne à realidade brasileira, Francisco de Oliveira, outro pensador que, como Hobsbawm, avalia que o capitalismo não é eterno e precisamos lutar para construir novas relações sociais, assinala que, ao contrário do que querem nos fazer crer - que política é coisas de especialistas -, é crucial resgatar a capacidade de fazer política. É neste ponto que o pensamento de esquerda e suas organizações encontram dificuldade por debilidade de análise ou por estreiteza de horizontes. Para Oliveira impõe-se

\footnotetext{
“a busca do consenso perdido: de que somos uma nação e não um conglomerado e consumidores. Cabe à universidade um importante papel nesta luta. (...) O malabarismo neoliberal da última década, no vagalhão mundial globalitário, desestruturou perigosamente o Estado e pode levar de roldão a Nação. A universidade é o lugar do dissenso, em primeiro lugar, dissenso do discurso do 'pensamento único'. Passo insubstituível para um novo consenso sobre a Nação, que é obra da cidadania, mas que pede e requisita a universidade para decifrar os enigmas do mundo moderno" (Oliveira, 2005, p. 70).
}

Na imperfeição da luta política, por fim, o desafio da travessia é articular lutas por reformas estruturais, conhecidas e disputadas ao longo do século XX, de natureza emancipatória com políticas de caráter distributivo. Não se trata de negar a urgência e a necessidade de políticas como o Bolsa Escola e outros similares. O dramático é que, com se vem reiterando, no passado e no presente, estas políticas atacam os efeitos precariamente, sem mover as causas ou determinações estruturais. Este tem sido o 'ovo de serpente' do governo Lula, em cuja biografia poderá pesar não só, como mostra Kuenzer, a continuidade das políticas de seu antecessor, ainda que mais universais e mais bem coordenadas, mas a responsabilidade de ter esfacelado o campo de esquerda e seu acúmulo 
de luta ao longo do século XX. Os indicadores do esfacelamento das forças de esquerda são inequívocos. Por certo, isto também não se deve somente aos descaminhos do governo Lula. É a própria esquerda que precisa se interrogar de sua precária capacidade de dar rumo ao governo dentro de um projeto nacional popular.

Francisco de Oliveira nos dá o horizonte da tarefa que nos cabe:.

“A disputa pelos sentidos da sociedade está de novo em ponto de ebulição. O Brasil é um remoto lugar desta disputa, e se enganam gravemente os que pensam que a nossa especificidade nos protege da crise global, que há um 'jeitinho brasileiro' para a crise. Cabe-nos enfrentar esse desafio, porque ninguém fará em nosso lugar" (Oliveira, 2005, p. 71).

Este desafio tem dimensões políticas, econômicas, culturais, educativas, mas o compromisso é ético. Trata-se de não negar ou renegar valores que são daqueles que lutam pela igualdade de condições de produção da existência de cada ser humano, em qualquer tempo ou espaço.

\section{Notas}

1 Professor titular aposentado da Universidade Federal Fluminense (UFF), Niterói, Brasil, e professor adjunto no Programa de Pós-graduação em Políticas Públicas e Formação Humana (PPFH) da Universidade do Estado do Rio de Janeiro (Uerj), Rio de Janeiro, Brasil. Doutor em Educação: História, Política, Sociedade pela Pontifícia Universidade Católica de São Paulo (PUC-SP). < gfrigotto@globo.com >

Correspondência: Universidade do Estado do Rio de Janeiro (Uerj), Centro de Educação e Humanidades, Faculdade de Educação, Programa de Pós-graduação em Políticas Públicas e Formação Humana. Rua São Francisco Xavier, 524, bloco B, $12^{\circ}$ andar, Maracanã, Rio de Janeiro, Brasil, CEP 20550-900.

$2 \mathrm{O}$ fetiche tecnológico se expressa pela autonomização da tecnologia mascarando as relações sociais de classe que a definem, a produzem e apropriam privadamente. Dele decorre o determinismo tecnológico que, como assinala Carlos Paris (2002), passa a idéia de que os problemas da humanidade hoje podem ser resolvidos apertando um botão. Determinismo esse que encobre o aprofundamento da violência de classe.

3 O termo competência, para Aurélio Buarque de Holanda Ferreira (1975), Novo Dicionário de Língua Portuguesa, designa "qualidade de quem é capaz de apreciar e resolver certo assunto, fazer determinada coisa; capacidade, aptidão, idoneidade".

4 Para uma análise crítica da noção da pedagogia das competências e suas implicações para a formação dos trabalhadores, ver Ramos (2002). 
5 Nada mais explícito em termos de mistificação ideológica do que a síntese feita por Moraes: "A empregabilidade é um conceito mais rico do que a simples busca ou mesmo a certeza de emprego. Ela é o conjunto de competências que você comprovadamente possui ou pode desenvolver - dentro ou fora da empresa. É a condição de se sentir vivo, capaz, produtivo. Ela diz respeito a você como indivíduo e não mais à situação, boa ou ruim da empresa - ou do país. É o oposto ao antigo sonho da relação vitalícia com a empresa. Hoje a única relação vitalícia deve ser com o conteúdo do que você sabe e pode fazer. O melhor que uma empresa pode propor é o seguinte: vamos fazer este trabalho juntos e que ele seja bom para os dois enquanto dure; o rompimento pode se dar por motivos alheios à nossa vontade. (...) [empregabilidade] é como a segurança agora se chama" (Moraes, 1998, p. 57).

6 Ver, a esse respeito, a análise crítica de Chauí (1993).

7 Ver, sobre este processo, a análise de Frigotto, Ciavatta e Ramos (2005a; 2005b; 2005c).

8 Do ponto de vista teórico-metodológico, na abordagem do materialismo histórico, as categorias particularidade e singularidade assumem centralidade, pois por elas é que se podem superar as análises de cunho economicista e lógico-estrutural.

9 Ao leitor interessado em aprofundar a questão, indicamos de Florestan Fernandes as obras: Capitalismo dependente e classes sociais na América Latina (1972); A revolução burguesa no Brasil: ensaios de interpretação sociológica. (1974) e Brasil em compasso de espera: pequenos escritos políticos (1980). Também é importante consultar a rigorosa recuperação do pensamento de Florestan sobre estas categorias desenvolvida por Mirian Limoeiro Cardoso. (2006). Das obras de Francisco de Oliveira, destacamos especialmente: Crítica à razão dualista: o ornitorrinco (2003); O elo perdido: classe e identidade de classe (1987) e Os direitos do antivalor (1998)

10 Não é objeto deste breve texto nos determos em detalhes do debate clássico e atual sobre imperialismo. Partimos, todavia, da compreensão de que, embora Marx escreva a sua obra antes da era imperialista, nela estão as pistas posteriormente desenvolvidas por Lenin e Trostki, Mandel, entre outros.

\section{Referências}

BELL, Daniel. O advento da sociedade pós-industrial. Rio de Janeiro: Cultrix, 1973.

CARDOSO, Mireian Limoeiro. Capitalismo dependente, autocritica burguesa e revolução em Florestan Fernandes. São Paulo: IEA, s/d. Disponível em: <www.iea.usp/br/artigos $>$.
CASTELLS, Manuel. A era da informação: economia, sociedade e cultura. 3 v. São Paulo: Paz e Terra, 1999.

CHAUÍ, Marilena. Vocação política e vocação científica da universidade. Educação Brasileira, Brasília, v. 15, n. 31, p. 1126, 1993. 
DRUCKER, Peter. A sociedade pós-capitalista. São Paulo: Pioneira, 1993.

FERNANDES, Florestan. Capitalismo dependente e classes sociais na América Latina. Rio de Janeiro: Zahar, 1972.

- A revolução burguesa no Brasil: ensaios de interpretação sociológica. Rio de Janeiro: Zahar, 1974.

Brasil em compasso de espera: pequenos escritos políticos. São Paulo: Hucitec, 1980.

Diretrizes e bases: conciliação aberta. Revista Sociedade e Universidade, São Paulo: Associação Nacional de Docentes de Ensino Superior (Andes), v. 1, n. 1,1991 .

FIORI, José Luiz. O nome aos bois. Fundação Perseu Abramo. São Paulo, 2002.

FRIEDMAN, Milton. Capitalismo e liberdade. São Paulo: Nova Cultural, 1985..

FRIGOTTO, Gaudêncio. Educação tecnológica e o ensino médio: concepções, sujeitos e a relação quantidade/qualidade. Projeto de Pesquisa. CNPq, Uerj, 2007.

FRIGOTTO, Gaudêncio; CIAVATTA, Maria (Orgs.). A formação do cidadão produtivo: a cultura do mercado no ensino médio técnico. Brasília: Inep, 2006.

FRIGOTTO, Gaudêncio; CIAVATTA, Maria; RAMOS, Marise N. A política de educação profissional no Governo Lula: um percurso histórico controvertido. Educação \& Sociedade, v. 26, n. 92, p. 1.087-1113, out. 2005a.

A gênese do decreto $\mathrm{n}^{\circ} 5.154 / 2004$ : um debate no contexto controverso da democracia restrita. Trabalho Necessário, ano 3, n. 3, 2005b.

(Orgs.). Ensino

médio integrado: concepção e contradições. São Paulo: Cortez, 2005c.
HAYEK, Frederic. Liberdade de escolher. Rio de Janeiro: Record, 1980.

O caminho da servidão. Rio de Janeiro: Instituto Liberal, 1987.

IANNI, Otávio. Era do globalismo. Rio de Janeiro: Civilização Brasileira, 2001.

JAMESON, Fredric. Pós-modernismo: a lógica cultural do capitalismo tardio. São Paulo: Ática, 1996.

LENIN, Vladimir. Obras escogidas, Moscou: Progresso, 1977.

LÖWY, MICHAEL. A teoria do desenvolvimento desigual e combinado. Tradução Henrique Carneiro. Actuel Marx, n.18 p. $73-$ 80, 1995.

The politics of combined and unevem development. London: New Left Books, 1981.

MANIR, Mônica. Perdemos 160 mil jovens por ano. O biscoito fino no olho gordo do mundo. Sala de imprensa. Unicamp. Campinas. Disponível em: <www.Unicamp.br/ unicamp/unicamp $>$. Acesso em: 27 abr 2007.

MORAES, Carlos. Emprego ou empregabilidade. Revista Ícaro Brasil, n. 171, p. 53-57, 1998.

NEVES, Lúcia Maria Wanderley (Org.). Educação e política no limiar do século XXI. Campinas: Autores Associados, 2000.

OLIVEIRA, Francisco de. O elo perdido: classe e identidade de classe. São Paulo: Brasiliense, 1987.

Os direitos do antivalor. Rio de Janeiro, Vozes, 1998.

Crítica à razão dualista: o ornitorrinco. São Paulo: Boitempo, 2003.

. Em busca do consenso perdido: democratização e republicanização do Estado. 
In: FIOD, Edna. Maciel et al. (Orgs.). Traços do trabalho coletivo. São Paulo: Casa do Psicólogo, 2005. p. 61-72.

PARIS, Carlos. O animal cultural. São Carlos: Ed. UFSCAr, 2002.

PAULANI, Leda. Modernidade e discurso econômico. São Paulo: Boitempo, 2005.

O projeto neoliberal para a sociedade brasileira: sua dinâmica e seus impasses. In: LIMA, Julio César França; NEVES, Lúcia Maria Vanderlei. Fundamentos da educação escolar do Brasil contemporâneo. Rio de Janeiro: Fiocruz, 2006. p. 67108.

POCHMANN, Márcio. Economia brasileira hoje: seus principais problemas. In: LIMA, Julio César França; NEVES, Lúcia Maria Vanderlei. Fundamentos da educação escolar do Brasil contemporâneo. Rio de Janeiro: Fiocruz, 2006.
O fenômeno do desemprego no Brasil: diagnóstico e perspectivas. In: BEDIN, Gilmar Antonio (Org.). Reestruturação produtiva, desemprego no Brasil e ética nas relações econômicas. Ijuí: Ed. Unijuí, 2000a. p. 35-108.

A batalha pelo primeiro emprego: as perspectivas e a situação atual do jovem no mercado de trabalho. São Paulo: Publisher Brasil, 2000b. v. 1 .

Tecnologia e emprego: algumas evidências sobre o caso brasileiro. São Paulo: Contexto, 2004.

RAMOS, Marise N. Pedagogia das competências: autonomia ou adaptação. São Paulo: Cortez, 2002.

TOFFLER, Alvin. A empresa flexível. Rio de Janeiro: Record, 1985.

VERISSIMO, Luis. Fernando. Fora, povo! O Globo, Rio de Janeiro, 30 ago. 2007, p. 7 